\title{
LOWER LIMB ARTHRODESES IN HAEMOPHILIA
}

\author{
G. R. HOUGHTON, R. A. DICKSON \\ From the Nuffield Orthopaedic Centre, Oxford
}

\begin{abstract}
Sixteen severely haemophilic patients have undergone arthrodesis of one joint of the lower limb in the period 1966 to 1976. There have been nine arthrodeses of the knee and seven of the ankle. The follow-up period was from nine months to eight years. The arthrodeses were secured by internal fixation. The method was not without complications, but a satisfactory bony union resulted in all cases without further surgical intervention.
\end{abstract}

During the ten years 1966 to 1976 there have been 822 admissions to the haemophilia service of the Nuffield Orthopaedic Centre, for acute episodes of bleeding. The anatomical distribution of these haemorrhages is shown in Table I. Haemarthroses of the knee account for 38.7 per cent of the total, and repeated bleeds into this joint lead to gross degeneration (Fig. 1).

Table I. Acute haemorrhages 1966-1976

\begin{tabular}{|l|r|r|}
\hline & Number & Per cent \\
\hline Joints & 318 & 38.7 \\
Knee & 187 & 22.7 \\
Elbow & 106 & 13.0 \\
Ankle & 24 & 2.9 \\
Shoulder & 20 & 2.4 \\
Wrist & 14 & 1.7 \\
Miscellaneous & & \\
Soft tissue & 48 & 5.8 \\
Iliopsoas & 31 & 3.8 \\
Forearm & 31 & 3.8 \\
Calf & 30 & 3.6 \\
Thigh & 13 & 1.6 \\
Miscellaneous & 822 & 100 \\
\hline TOTAL & & \\
\hline
\end{tabular}

Haemophilic arthropathy of the ankle may result from recurrent haemarthroses, or from recurrent haemorrhages into the calf muscles with contracture and secondary degeneration of the ankle (Fig. 2). Bleeds into these tissues account for 16.8 per cent of the total. The knee and ankle are thus involved in over 55 per cent of musculoskeletal bleeds in haemophilia; without expenditious treatment progressive degeneration is likely in these weight-bearing joints.

Chronic haemophilic arthropathy of the knee or ankle leads to painful contractures of these joints, with an increased risk of further haemarthroses because of synovial thickening and the abnormal stresses involved in walking with deformed joints. Non-operative methods such as reversed dynamic slings (Stein and Dickson 1975) may succeed in correcting contractures of the knee if joint incongruity is not gross. Operation on the soft tissues has successfully corrected ankle contractures (Field, Enneking and Rothstein 1963; France and Wolf 1965) when joint destruction was not severe. These conservative methods of treatment are inadequate when marked secondary arthritic changes are present.

Arthrodesis of the knee or ankle is a successful procedure for painful contractures of these joints in the presence of haemophilic arthropathy, and the following details illustrate our experience of this method.

\section{MATERIALS AND METHODS}

The material for this study is based upon sixteen arthrodeses carried out on haemophiliacs during the ten years 1966 to 1976 . All patients had severe classical haemophilia. Twelve patients had no circulating factor VIII and the remaining four had 20,2,1 and 6 per cent levels of factor VIII. None of the patients had circulating antibodies to factor VIII. There were nine arthrodeses of the knee (five left and four right) and seven of the ankle (two left and five right). With minor variations the same operative techniques were carried out on all the knees and all the ankles. The mean follow-up period was four years (range nine months to eight years). The mean age of the patients at the time of operation was thirty-four years.

The operative indications are shown in Table 11 . The main indication for operation in all cases was pain. Additional indications were recurrent haemarthroses, marked deformity and instability. The range of joint movement was restricted in all cases with a mean value of 31 degrees for the knee compared with 103 degrees on the non-operated side, and a mean value of 10 degrees for the ankle compared with 51 degrees on the non-operated side.

All patients could walk independently with the exception of two patients in wheelchairs and one on crutches. 

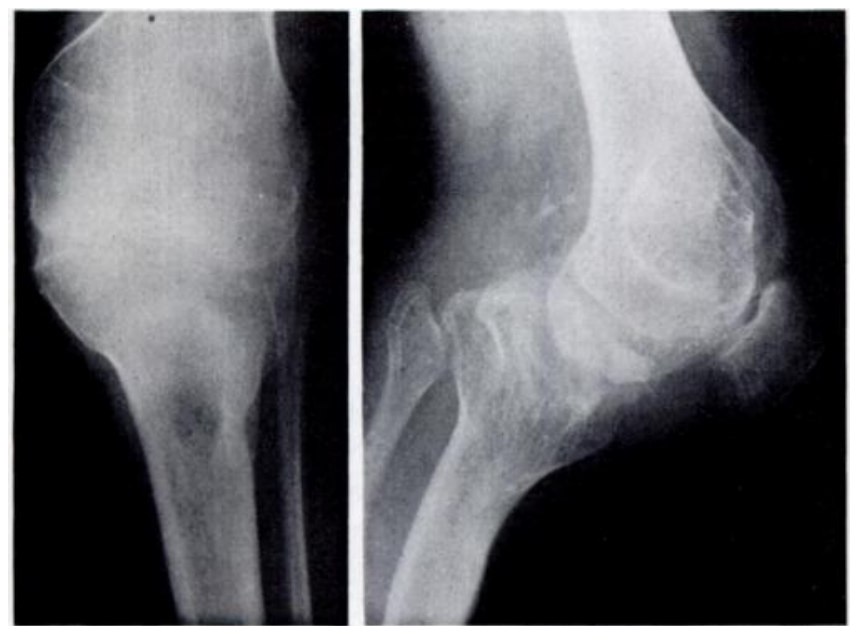

Fig. 1

Radiographs of the knee before operation showing severe haemophilic arthropathy.

In all cases there were radiographic changes diagnostic of haemophilia (Figs. 1 and 2). In the knee the characteristic features were posterior subluxation and lateral rotation of the tibia; there was a widened intercondylar notch, squaring off of the lower end of the patella, diminution of joint space, subchondral sclerosis, subchondral

Table II. Indications

\begin{tabular}{|l|c|c|c|}
\hline & Knees & Ankles & Per cent \\
\hline Pain & 9 & 7 & 100 \\
Haemarthroses & 3 & 2 & 31 \\
Deformity & 3 & 0 & 19 \\
Instability & 1 & 0 & 6 \\
\hline
\end{tabular}

cyst formation, juxta-articular porosis and metaphysial widening. Osteophyte formation was usually marked. In the ankle there were radiological signs of secondary osteoarthrosis, and the characteristic feature of a "boat-shaped" talus in five of the seven ankles. This appearance is due to moulding of the talus in equinus during growth.

\section{OPERATIVE TECHNIQUE}

Knee arthrodesis was performed by excision of the joint with removal of a wedge for correction of fixed flexion, and crossed-screw fixation (Fig. 3). For ankle arthrodesis, the joint was excised with removal of an anterior wedge for correction of any fixed equinus and the use of a fibular onlay graft as shown in Figure 4-the R.A.F. technique (Adams 1948). In addition, elongation of the tendo calcaneus was required in four patients.

Operations were performed under factor VIII cover and the use of a tourniquet, and dissection was carried out with an electrocautery. The wounds were closed in layers with continuous absorbable sutures and no drains (Duthie et al. 1973). The mean amount of factor VIII required during the operative period was 28631 units for knees and 24791 units for ankles.

The knees were arthrodesed at 10 to 30 degrees of flexion depending on coexistent deformity of the hip or ankle. The ankles were fused in the neutral position in three patients and at 5 to 30 degrees of flexion in the remaining four who had gross equinus deformity.

All patients with arthrodesis of the knee remained in plaster-ofParis long-leg casts for three months, then in polythene splints until there was clinical and radiological evidence of union. Similarly, all patients with ankle arthrodeses were immobilised in below-knee casts for eight weeks, then in a Yates polythene splint until union was complete.

\section{RESULTS}

The mean time to union was 5.7 months for knees and 3.9 months for ankles. All the arthrodeses united, but there were three cases of delayed union with the knees of seven, eleven and twelve months. The mean time to union was 3.5 months in the remaining six cases. There were no cases of delayed union in the ankles. Wound complications occurred in four patients. One knee developed a superficial haematoma and another a staphylococcal infection. Two ankles showed delayed healing of the wound of one and four months respectively.

Additional complications included one patient with a chest infection and one patient with serum hepatitis. Both these patients recovered with appropriate medical treatment.
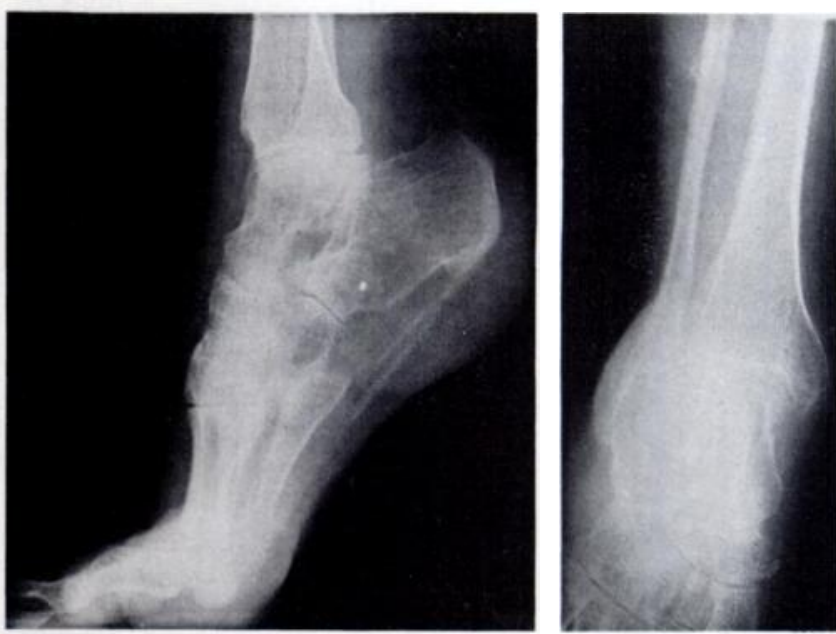

Fig. 2

Haemophilic arthropathy of the ankle, illustrating the boat-shaped talus.

\section{AN ANALYSIS OF WOUND COMPLICATIONS}

Case 1. Arthrodesis of the left knee at the age of twenty-five. Extensive blood-staining of plaster occurred, and on the seventh day after operation 60 millilitres of serosanguinous fluid were aspirated from the wound. On the fourteenth day, 120 millilitres of clot were evacuated from the subcutaneous tissues; no skin necrosis was present and the wound showed satisfactory healing within one month.

Case 2. Arthrodesis of the right knee at the age of fifty. Two months after operation blood-staining of plaster was noted and the wound had an area of purulent skin necrosis measuring $1 \times 8$ centimetres. A culture grew Staphylococcus aureus. With systemic chemotherapy and daily Eusol dressings, the wound healed within ten weeks. No skin graft was required.

Case 3. Arthrodesis of the right ankle at the age of twenty-two. On inspection of the wound at fourteen days, sloughing was noted over an area $2 \times 10$ centimetres. The wound was debrided, and the necrotic tendo calcaneus was excised under factor VIII cover. The wound had healed without skin graft by four months after operation.

Case 4. Fusion of the right ankle at the age of forty-one. There was superficial sloughing of the lower end of the wound which responded to daily Eusol dressings. By one month the wound had healed. 

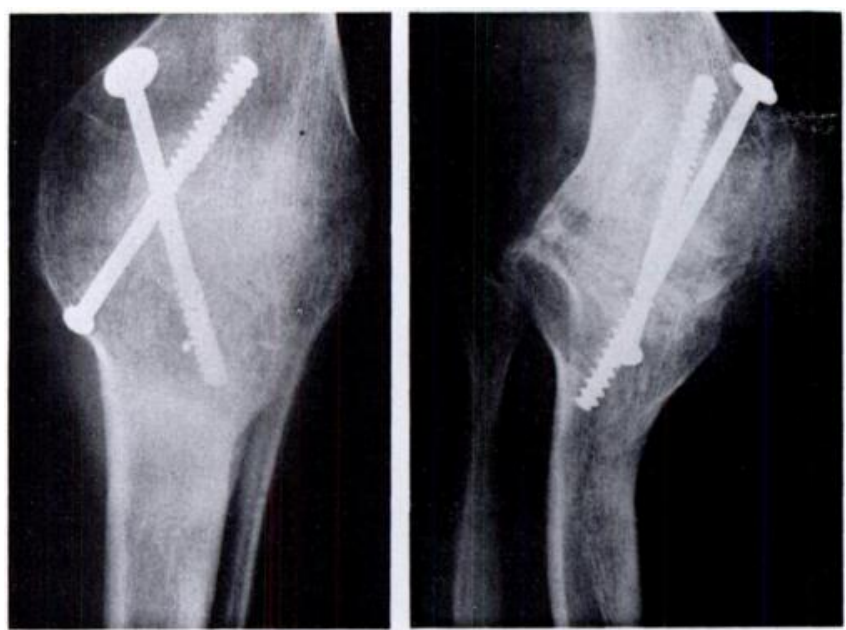

Fig. 3

Position of arthrodesis of the knee shown in Figure 1.

\section{DISCUSSION}

With the present trend in favour of home therapy for haemophiliacs with self-administration of factor VIII, premature joint degeneration is seen less often than it was ten years ago. However, we continue to see deforming haemophilic arthropathy, affecting particularly the knees and ankles. Arthrodesis for a severely affected joint offers the patient stability with complete relief of pain. It also reduces the incidence of early arthritis in the other joints of that limb (Green, Parkes and Stinchfield 1967). We therefore favour a method of internal fixation for fusion of a haemophilic joint. The Charnley method of arthrodesis with external compression clamps and percutaneous pins is the most popular method of knee and ankle arthrodesis in this country (Charnley 1960). However, all reports of this method cite infection of the pin track as a complication (Ratliff 1959; Charnley 1960). Haemorrhage and infection of the pin track is a theoretical danger in the haemophiliac and is best avoided.

Despite meticulous attention to surgical detail, four complications occurred, probably due to haematomata during the healing process. Three of these occurred at the beginning of the series and probably reflected the lack of experience at that time in controlling factor VIII during major operations. Nevertheless, all wounds healed without further extensive surgical intervention.

There were no late complications in this series. This is important as the subsequent possible development of factor VIII antibodies would be an absolute contraindication to a further operation.

Replacement arthroplasty of the knee and ankle has a high complication rate (Insall et al. 1976) and surgical correction of these complications may be required. The definitive procedure of arthrodesis for the painful and stiff knee or ankle avoids these complications, and reduces the need for factor VIII replacement.
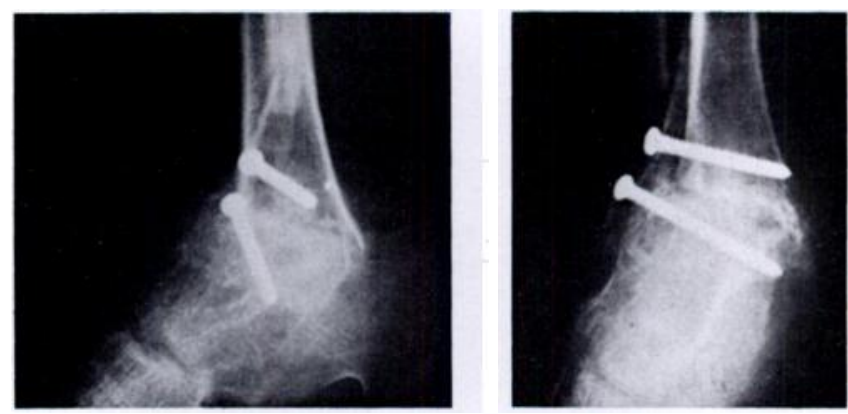

Fig. 4

Position of arthrodesis of the ankle shown in Figure 2.

We would like to thank Professor R. B. Duthie, under whose care all the patients were treated, for his help and encouragement in the preparation of this paper.

\section{REFERENCES}

Adams, J. C. (1948) Arthrodesis of the ankle joint. Journal of Bone and Joint Surgery, 30-B, 506-511.

Charnley, J. (1960) Arthrodesis of the knee. Clinical Orthopaedics, 18, 37-42.

Duthie, R. B., Matthews, J. M., Rizza, C. R., and Steel, W. M. (1973) The Management of Musculo-Skeletal Problems in the Haemophilias. Oxford: Blackwell Scientific Publications.

Field, R. C., Enneking, W. F., and Rothstein, G. (1963) Elective surgery in hemophilia. I, Correction of talipes equinus deformity. Journal of American Medical Association, 185, 628-630.

France, W. G., and Wolf, P. (1965) Treatment and prevention of chronic haemorrhagic arthropathy and contractures in haemophilia. Journal of Bone and Joint Surgery, 47-B, 247-255.

Green, D. P., Parkes, J. C., and Stinchfield, F. E. (1967) Arthrodesis of the knee. Journal of Bone and Joint Surgery, 49-A, $1065-1078$.

Insall, J. N., Ranawat, C. S., Aglietti, P., and Shine, J. (1976) A comparison of four models of total knee-replacement prostheses. Journal of Bone and Joint Surgery, 58-A, 754-765.

Ratliff, A. H. C. (1959) Compression arthrodesis of the ankle. Journal of Bone and Joint Surgery, 41-B, 524-534.

Stein, H., and Dickson, R. A. (1975) Reversed dynamic slings for knee-flexion contractures in the haemophiliac. Journal of Bone and Joint Surgery, 57-A, 282-283. 